\title{
The Role of Sports Biology in Training
}

\author{
Mir Sharif Hasan* \\ Student Counselor (Sports) North Bengal International University Rajshahi-6206, Bangladesh. \\ *Corresponding Author: Mir Sharif Hasan, Student Counselor (Sports) North Bengal International \\ University Rajshahi-6206, Bangladesh.
}

\begin{abstract}
The human organism and its relations to the environment as a complex and integrated biological system.

Much the same as other living organisms, the human organism is characterized by the phenomena of life. These are metabolism from the nutrients via all anabolic and catabolic processes up to the excretion of wastegrowth and development, reproduction and the ability of reaction to environmental stimulus.

But unlike other living beings man as a social being, Possesses very highly refined synthesizing properties, which at once deeply distinguish him from animals. The main difference characteristic is man's higher nervous activity related with human speech. The word, speech, underlies man's ability (The ability of his brain) to form general ideas and concepts and to think abstractly and logically. And by thinking, man discovers the laws of nature. Which enable him to change the environment according to his own will.
\end{abstract}

Keywords: Human Organism, Metabolism, Intake of nutrients, Man's higher nervous activity, Human being thinks abstractly and logically integrated biological system.

\section{INTRODUCTION INTO SPORTS BIOLOGY}

The human organism is a complex and integrated biological system. Like other multicellular organism man consists of cells as the morphological and functional elementary unit. Cells and intercellular substances form tissues, tissue make up organs and organs unite in systems of organs corresponding to their phylogeny or functional reprocity. Finally all the systems of organs, like locomotors system (Skeleton and muscular system), Cardiovascular system, respiratory system, urogenital system, digestive system, nervous system and endocrine system form the organism as a whole.

These classical considerations are more or less related to the structure of the human organism. But from the physiological point of view the different parts of the organism never function independently. There are various close connections and interactions between the different parts, system or smaller units of the organism.

The relations between the various parts of the organisms can be demonstrated by the coordinated changes in other systems.

Intensified activity of one organ, or system of organs is accompanied by changes in other systems. As an example, in all types of sports activities, muscular work plays a major part. But it is well-known that muscular work is accompanied by increased muscular metabolism for energy liberation required for the mechanical work. This lead to coordinated changes in the activity of the cardiovascular, the respiratory, the excretory and other systems, continuously regulated and controlled by the nervous and endocrine systems.

The interdependence between the various tissue, organs and system of organs manifests itself in diseases or injuries. Any changes in one particular organ affects other systems of organs. So the localized disease or disturbance of one specific tissue or organ sometimes impairs the entire organism, for instance localized inflammation of the tonsils by bacteria causes fever, weakness in the muscles and joints, general weariness and other phenomena.

This was the basis for the rule in biology that. In man's functional capacity the weakest organ is the restricting organ. 
But the human organism is not only a structural and functional unit in itself (related to the complicated interplay between the different parts of the organism). The organism and the external conditions essential for its existence also constitute an entity.

The different external factors such as the complex climatic phenomenon, socially determined factors, like working conditions housing, composition and amount of nutrients hygienic conditions continuously affect the organism.

Unlike animals man can deliberately change his surroundings, like artificial irrigation with the accompanying climatic alterations etc. But the organism has to maintain an equilibrium between the internal conditions (Mentioned above) and the external environment.

This equilibrium between internal and external condition (or endogenic and exogenic factors) is called homeostasis. In a broader sense this term is explained as the interaction of physiologic processes resulting in constant endogenous surroundings for example in the course of life there is water balance i.e. intake and out of water are equalized the biochemical and morphological composition of the blood is also well out balanced under normal circumstances. The body temperature is typical for homeostasis. It is kept 37 degrees centigrade independent of outer and inner faction.

Homeostasis or Constancy of endogenous factors despite the continuous action of external stimuli on the organism is easily understood if one considers that all parts of the organism are inter connected by the nervous and humoral system. Both systems and their interactions play a major part in controlling and regulating body equilibrium that is homeostasis between internal and external conditions.

It has recently become common practice to apply the pattern of a block diagram of cybernetics for better understanding of the control the regulation of these complicated interrelations.

In our organism most of these regulations are of a reflex nature and operate on the principle of self regulation (unconditioned and conditioned reflexes). Many functions are regulated automatically, i.e, independent of our consciousness such as blood pressure, pulse rate the respiratory values are maintained at definite level, corresponding to the prevailing state of the organism; the metabolism is also related to the special needs etc. other functions are regulated by will i.e, by voluntary control of the cerebral cortex.

But the relationship between the organism and its external environment to keep continuous homeostasis is not only affected directly by the nervous system but also chemically by the food consumed and the air inhaled. On the other hand certain substances produced by special glands (endocrine) are transported by the blood and play a certain role in maintaining body equilibrium. Thus unified neurohumoral regulation of functions is yet another characteristic of the human organism.

\section{CONCLUSION}

Sports biology is an important subject within the branch of sports science. Specially it deals with the training requirement in respect of physical and Psychological in different sports events. It also helps to maintain the physical qualitative measurements during the long term training plan. Sports coaches, trainers and officials get adequate biological information from this subject for their work and satisfactory sports performance.

\section{REFERENCES}

[1] Harre, D. et. al. Traningslehre. Berlin. Sportverlag 1970.

[2] Paerisch, M, Einfuhrung in die physiologie des menschen, Leipzig. Deutsche Hochschule fur korperkultur, 1970.

[3] Yoshida, T., Nagata, A. Muro M., Takeuchi, N. and Suda, Y, (1981) the validity of the anaerobic threshold determination by a Douglas bag method compared with arterial blood lactate concentration: European Journal of Applied Physiology, 46, 423-430.

[4] Goldberg, A. L. (1968) Protein synthesis during work-induced growth of skeletal muscle. Journal of Cell biology 36, 653-658.

[5] Hall-Craggs, ECB (1970) the longitudinal division of fibre in over loaded rat skeletal muscle. Journal of Anatomy, 107, 459-470.

[6] Luthi J.M. Howald, H., Classen, H., Rosler, K., Vock, P., and Hopper, H., (1986) Structural changes in skeletal muscle tissue with heavy-resistance exercise. International Journal of Sports medicine, 7, 123-127. 
[7] Schmidtbleicher, D., and Haralambie G., (1981) changes in contractile properties of muscle after strength training in man. European Journal of Applied physiology 46, 221-228.

[8] Boobis, L., Williams, C., and Wotton, S.A. (1983) Human muscle metabolism during brief maximal exercise. Journal of Physiology, 338, 21P-22P.

Citation: Mir Sharif Hasan. "The Role of Sports Biology in Training" International Journal of Sports and Physical Education (IJSPE), vol 6, no. 4, 2020, pp. 13-15. doi: https://doi.org/10.20431/2454-6380.0604003.

Copyright: (C) 2020 Authors. This is an open-access article distributed under the terms of the Creative Commons Attribution License, which permits unrestricted use, distribution, and reproduction in any medium, provided the original author and source are credited. 